\title{
Getting in, Getting on, Getting out? Women as Career Scramblers in the UK Film and Television Industries
}

\author{
Leung Wing-Fai, Rosalind Gill and Keith Randle
}

\begin{abstract}
This paper looks at the predominance of freelancing in the film and television industries as a lens to examine the persistence of gender inequalities within these fields. Previous research has indicated that women fare better in larger organisations with more stable patterns of employment, and in this paper we explore why that might be the case, by focusing on the experiences of female freelancers at a moment when project-based, precarious work and informal recruitment practices are increasing in the UK film and television sector. We highlight in particular the ways in which gender inequality is mediated by age and parental status, and the impact of intersectional identities on women's ability to sustain a career in film and television.
\end{abstract}

\section{Introduction}

The free agent scrambles, bee-like, from opportunity to opportunity without regard to boundaries. (Jones and DeFillippi, 1996: 89)

The paper draws on more than 100 interviews with people in the film and television industry in the UK, and takes an intersectional approach. It focuses on the challenges posed by 'informality' in recruitment and as a means of finding work, pointing to the ways in which reputation, networking and homophily structure who gets in and gets on within these fields. It also looks at the issue of parenting, highlighting the practical difficulties of combining motherhood with a career in film or television, alongside subtle forms of discrimination that affect mothers and women more generally - highlighting particularly the ways in which not hiring women can be presented as 'rational' or 'understandable' producing what we call 'reasonable sexism'. It further shows how an entrepreneurial ethic and an antipathy to 'whinging' mean that difficulties associated with inequality or with parenting are rarely voiced and are devolved to individuals to resolve themselves. In this way the paper contributes to understanding how inequalities are both unmanageable and unspeakable within film and television production. 
In recent years a number of terms have been coined to try to capture the ways in which working lives and career patterns are changing. Portfolio careers, project-based working and boundaryless careers are just some of the attempts to create a lexicon that speaks to what Beck (2000) has characterised as 'the Brave New World of work'. In this, short-term, discontinuous employment marked by precariousness and insecurity is 'discursively sweetened' by talk of entrepreneurialism and risk-taking, as 'cool, creative and egalitarian' work (Gill, 2002). While the people most affected by these changes have been the lowest paid workers, struggling in 'McJobs', among skilled and professional workers those in the cultural and creative industries (CCI) have been at the forefront of this trend towards 'precarisation'. As Ross (2009) has argued, freelance 'creatives' have become 'new model workers' in contemporary capitalism, built upon the idea of the musician's gig: 'nice work if you can get it'.

In this paper we look at the predominance of freelancing in the film and television industries as a lens to examine the persistence of gender inequalities within these fields. This paper aims to examine the effects of freelance work, focusing specifically on women's employment in the UK film and television sector. Previous research has indicated that women fare better in larger organisations with more stable patterns of employment, and here we want to explore why that might be the case, by focusing on the experiences of female freelancers at a moment when project-based, precarious work is increasing in the UK film and television sector. Fewer women than men 'get in' to these industries, the way that they 'get on' is often different, and, increasingly, it seems women 'get out' of film and television after relatively short 'careers'.

The paper adopts an intersectional (Brah and Phoenix, 2004; Crenshaw, 1991) ethic, which seeks to understand the connections between multiple axes of oppression and exclusion, on the understanding that these are not simply 'additive' but constitute distinct experiences and subjectivities. It examines how gender acts in conjunction with other salient personal characteristics, and as such problematises theoretical frameworks that focus on single issues within a diversity agenda. Here we focus on intersections between gender, age and parental status. The paper is informed by a broader study funded by the European Social Fund Diversity in Practice project and conducted by the Creative Industries Research \& Consultancy Unit (CIRCU) at the University of Hertfordshire, UK (Randle, Leung and Kurian, 2007), which examined in detail class, race and ethnicity, and disability, in the context of film and television employment. The data comprise more than 100 semi-structured 
interviews conducted in 2006 with some interviewees revisited in 2011 - the latter designed to explore the effect of recent changes including the global financial crisis and associated recession and the impact of the Single Equalities Act in the UK- on the film and television industry. Interviews were conducted with representatives from film and television sector bodies and broadcasters as well as practitioners in the industry and included 51 female interviewees (see Randle, Leung and Kurian, 2007 for more information about the methodology).

This paper is divided into four sections. In the first we provide a brief overview of gender inequalities in the film and television industries. We then examine typical work practices and the dominance of freelancing in film and television production. We focus on our data in the following two sections looking first at how a number of features of the film and television industry's informality may contribute to inequalities in the numbers, status and pay of women and men, and second at the variety of ways in which parenting may impact upon women's life chances in film and television. Here we attempt to move current debates beyond discussion of the practical challenges of parenting while holding down a job in these fields, to also consider the subtle kinds of discrimination that can affect all women - regardless of whether they are mothers - and which render children and caring responsibilities ‘unspeakable' (Gill, 2015). Finally, there is a brief conclusion.

\section{Gender inequalities in the film and television industries}

Women are underrepresented in the film and television industries, particularly in key creative and decision-making roles (see Conor, Wreyford, this volume, and editors' introduction). In the USA, the celluloid ceiling report (Lauzen, 2012) which examines employment in the top 250 films each year, found that women represented only $5 \%$ of directors, $14 \%$ of screenwriters and just $4 \%$ of cinematographers. In the UK, the figures are similar. The British Film Institute's Statistical Yearbook (2013) records that only 7.8\% of British films were directed by a woman and $13.4 \%$ written by a woman. From the Skillset employment census of the creative media sector in 2012, women represented only $13 \%$ of camera department, $5 \%$ of lighting (down from 10\% in 2009) and 13\% of sound (Creative Skillset, 2012: 15). By contrast women are concentrated and overrepresented in wardrobe (73\%) and make up/hairdressing (81\%) - fields that are well documented as the most precarious, with the highest levels of freelancing (Creative Skillset, 2012: 15). 
TV production has an overall representation of women that is somewhat better (particularly in the larger terrestrial broadcasters), yet inequalities are revealed as soon as one examines questions of seniority, contractual status and pay. Women are seriously underrepresented in more senior roles in television - something that is seen right across the CCI. Indeed, the Equalities and Human Rights commission's audit Sex and the Power (2011) found that women's representation in senior positions in the field of media and culture as a whole was only $15.1 \%$. As chief executives of media companies in the FTSE 350 they represented just $6.7 \%$. It is worth noting that women in this field are significantly better qualified than their male counterparts, with a greater proportion being graduates and an even more significant difference in the numbers of women, compared to men, with higher degrees (Skillset 2010a: 6). Moreover, women are significantly more likely to have undertaken industry-specific training. Nevertheless, women earn on average $15 \%$ less than their male colleagues and are much less likely to be promoted or to make it into senior positions (Skillset, 2010a: 6). This marked pay inequality holds true even when other factors are adjusted (controlled for), for example, the lower age profile of women in the workforce, an issue we will turn to now.

More complex, intersectional inequalities are becoming evident in which the effects of gender are mediated by other factors including age, relationship status and parental status. In a debate about women in television (Skillset, 2010b), the Executive Director of Skillset, Kate O’Connor, noted that the TV industry was better at recruiting women than at keeping them, leading to a distorted age profile in which $70 \%$ of men in the TV industry are over 35, whilst the largest proportion of women is in the 25-34 age group. One interpretation of this might be that a once male-dominated industry is now recruiting younger women, who have simply not yet had chance to 'get on' and work their way into the older age categories. However this benign reading is not borne out by the evidence, which notes the youthful and junior profile of female industry entrants, but does not see them progressing in line with their male peers. In fact women are 'haemorrhaging' from the industry in their late 30s and 40s. As a study by Sargent-Disc (2011: n.p.) puts it, women and men's experiences 'are different [...] and there is difficulty in retaining a large number of women beyond their 30s'. A Participant in our research noted:

I think at senior roles [...] there's still more men than women.

The further up you go, the less chances [the employers]'ll take on you [...] 
Women working in creative media are less likely than men to have dependent children living with them (23\% compared to 35\%), indicating that women may be leaving the sector after starting a family (Skillset, 2010a: 5). Perhaps reflecting the itinerant nature of an industry that requires production staff to work away from home for long periods of time, $81 \%$ of film workers have no dependent children (Skillset, 2010a: 19).

During the recession that marked the period between our first and follow-up interviews, the UK's TV industry contracted dramatically, a troubling experience for all affected. However, it is notable that women lost their jobs at a rate that was six times that of men, indicating the particular and heightened vulnerability of women in the industry. In the subsequent years, women's representation improved, going from a low of 27\% in 2009 to 36\% in 2012 (Creative Skillset, 2012) but the job losses cast a long psychological shadow in making women in the industry feel more 'disposable' than their male counterparts. All this indicates the complexity of understanding the reasons for women's continued underrepresentation, and their status as what Oakley (2013) has described as 'absentee workers', those people 'lost' to employment in the cultural and media industries by dint of their gender, class or ethnic origins.

\section{Freelance work in the UK film and television industries}

Film and television have been described as 'different industries with some important similarities and overlaps in their production and labour processes' (Randle, 2011: 145). In both cases the production process is frequently project-based with a set of common stages: pre-production (conception, design and planning), production, post-production (editing, adding music tracks and special effects) followed by broadcast (television) or exhibition (film). Individuals may move between these sectors, especially those involved in the production and post-production stages of a project. This is perhaps most obvious where the products are similar, for example in TV drama and feature film productions requiring crews made up of a range of common technical occupations (such as camera, hair and make-up, and lighting).

One of the shared experiences of growing numbers of people working in the film and television industries is of precariousness and job insecurity. This is especially the case in those occupations involved in production and post-production and less so in, for example, 
broadcasting where permanent employment within large broadcasting corporations is more common. An important development in the organisation of film and television has been the fragmentation which has resulted in an 'hourglass' shape where a relatively large number of people are employed (more often permanently) by a small number of sizeable TV broadcasters, satellite and cable companies or film majors, while an equally large number of others are employed by numerous small or micro businesses (Randle, 2011).

Increasingly workers in these fields, especially, but by no means limited to, those employed in the bottom half of the 'hourglass', are freelancers and work on short contracts that are counted in days or weeks rather than months. Indeed film and television workers - like other workers in the CCI - have become the poster children of 'precarity', iconic exemplars of a group that lives individualised 'risk biographies' in which all the uncertainties and costs are borne by them rather than by employers or the state; they are what Neff (2012) pertinently dubs 'venture labour'. As we discuss below, this mode of living requires constant attentiveness and vigilance to the possibility of future work, and heightened forms of network sociality (Wittel, 2001). It is, for many, a precarious existence, with many of our interviewees expressing anxiety about the flow of work, or about becoming sick and thus being unable to work.

The film industry has a long history as a project-based enterprise, marked by high levels of freelancing. Skillset reported that $90 \%$ of film production workers were freelancers (House of Lords Select Committee on Communications, 2010: 264). Skillset's research also shows that on average respondents had worked on three feature films in the previous twelve months. The majority of respondents had also worked on some other kind of audio-visual production (often TV or advertising). The project based nature of the majority of employment means that even established workers experience periods out of work (Skillset/UKFC, 2008: 16).

Changes in the competitive and regulative conditions of UK television during the 1990s have also engendered the dramatic increase in freelancing among the television workforce. The Communication Act 2003 made it mandatory for public sector broadcasters (PSBs) to commission $25 \%$ of their non-news programmes from independent production companies. The BBC pledged another $25 \%$ to be open to external competition under its commissioning slate entitled Window of Creative Competition (WOCC) (Ofcom, 2006: 9). The PSBs have achieved their quotas, resulting in the reduction in in-house commissioning and growth in the market share of the independent sector by 5\% to 46\% in the five years from 2005 (Ofcom, 
2010: 142). The reliance on freelancers varies considerably by sub-sectors of the television industry; over two-fifths (44\%) of the independent production workforce are freelance, but this drops to 19\% in terrestrial broadcast and 11\% in cable and satellite TV (Skillset, 2011: 4), further contributing to the 'hourglass' shape of employment structure we have discussed.

With the reduction in spending by PSBs and the decline of terrestrial television, there is likely to be further impact on project based, freelance working in the UK television sector. Research conducted for the Broadcast Training \& Skills Regulator, showed that many freelancers worked relatively little (CIRCU, 2008). One hundred and twenty freelancers in London and forty six in Scotland completed questionnaires during two events. Nearly half (46\%) in London worked fewer than 100 days a year. Roughly two thirds of freelancers (66\%) from London and Scotland worked fewer than 200 days during the previous year. This means that they were unemployed for about 12 weeks per year. Therefore, many freelancers are likely to feel the financial impact of the periods of unemployment. Even though project based work has been a longstanding feature of the film industry in the UK, the casualisation of television has made this common to both sectors (Grugulis and Stoyanova, 2010).

With the deregulation of the television industry and the growth of the independent sector (Grugulis and Stoyanova, 2010), the responsibility for training shifted from the broadcaster to the individual, as this interviewee explains:

[Until] 20 years ago, the BBC employed and trained everybody in the technical areas. That doesn't happen anymore. And whilst independent access and the freeing up of television have been good in many ways, there is always a downside to everything.

The high cost of training may pose an obstacle for some people aspiring to enter the sector. Training for the different roles within the sector is usually through formal training courses, degree education or on-the-job learning. There are no set paths into the industries. Work experience, working for free and low paid jobs at the beginning of media careers are common routes through which people enter the sector (see Randle and Culkin, 2009 for an account of similar arrangements in the US industry). Unpaid work experience may contravene National Minimum Wage requirements where an employment relationship is considered to exist and some employers may be acting illegally (something that has been the topic of much 
discussion, see Regan, Shade and Jacobson, this volume). The lack of financial support for training can lead to exclusion on the grounds of social class, geographical location, disability and economic marginality. As the sector is dominated by graduates, the increasing costs of completing a degree in the UK make this a potentially exclusionary route. Training for some technical grades is still gender biased as they are traditionally male occupations and women may not be encouraged to pursue these careers. In the next section we look in more detail at the informality of the sector, exploring how this may impact upon gender inequalities.

\section{Informality and unmanageable inequalities within film and television}

The most distinctive feature of recruitment in the sector is its informal, word of mouth nature, as film and television productions come under time and resources pressure. Working under time pressure is a particular a feature of employment in the sector; a project may get the 'green light' on a Friday and have to crew up for the following Monday to begin shooting. As a result, freelancers have to constantly pitch for work, using a variety of methods. Personal recommendations are seen to ensure quality; workers in the sector only recommend those they can trust.

It is important to note that unlike many other sectors, recruitment in the film and television industries is deregulated, informal and often ad hoc. It is often not a company or broadcaster who performs the function of hiring and firing on a daily basis. In some of the technical departments such as camera or lighting, the heads of department choose the crew. For example, a Director of Photography may choose the gaffer who will then be in charge of the electricians. Producers may be consulted if there is non-availability of the usual crew members and contacts. Equally, recommendations from colleagues may be sought. This practice produces 'semi-permanent groups' that move from job to job (Blair, 2000). The majority of those in the film production workforce (87\%) were recruited to their latest project through word of mouth, including $23 \%$ directly by the producer or director, $40 \%$ by the head of department or supervisor and $20 \%$ recommended by an individual or company that they had worked with before. Only 1\% was recruited through job advertisement (Skillset, 2010c:

10). This interviewee from camera crew sums up the practice:

Looking for work [...] no matter how well you're doing, the fact that you shot that great film last year isn't going to help you. You've still got to find your next job. It is a cliché $[\ldots .$.$] you're only as good as your last job. It's a lot of energy [...] if you$ haven't got the drive, you're not going to get there. There's a lot easier jobs to do. 
Another, working within the similarly structured US TV industry, explains how challenging this can be:

Doing the work is fun. Finding the work is the job

(quoted in Randle and Culkin, 2009).

Informal recruitment practices dominate. While an up to date resume is vital and film and television are increasingly graduate entry industries, a résumé and a degree are necessary but not sufficient. These are 'reputation economies' in which people are hired on the soft judgments of insiders about whether they are trustworthy, reliable and good to work with. Networks and contacts are the main means of gaining employment, which forms a barrier for fresh and diverse talent from underrepresented groups, as many may not have access to social events and opportunities. As some of our female interviewees pointed out, networking is a time-consuming and demanding requirement of freelancing: 'you need to maintain very strong links and networks with people to get the jobs', said one senior and very experienced TV researcher. The spaces for networking - particularly pubs - could also form challenging environments for women, and the requirement for 'compulsory sociality' (Gregg, 2006) after already long working days posed problems for everyone with caring responsibilities. One interviewee, a female, disabled filmmaker from a regional city, had decided to give up a film career as she explains in a follow-up interview in 2011,

It's hard for everybody but it's compounded with other things. I can't do the networking, going to film festivals, the being-there. So my decision not to be a filmmaker anymore is to do with diversity, disability and inclusion issues. I don't sit comfortably in the sector because of disability, and also as a woman, a single parent. I can't compete on the terms that this sector requires.

Another issue is the tendency towards homophily: the practice of insiders recruiting in their own image, or selecting candidates with whom they feel they have an easy rapport. Working relationships in the industry are forged on the basis of trust, which generally entails working with those one has worked with previously, or accepting a recommendation from such a person. This is a particular danger in (but not limited to) the very large number of small firms 
without formal recruitment procedures, HR functions or equal opportunities policies and monitoring and in those occupations where vacancies are not formally advertised. This could make it challenging for many women to break into such close-knit groups if the jobs have been dominated by men to date. As a consequence, male practitioners may be able to build up a longer work history than their female counterparts. Exclusionary patterns of hiring could, in this sense, emerge unconsciously, the outcome not of explicit sexism but of a network of trust relationships based on affect and tacit judgments such as 'he's a good bloke'. As one female camera operator put it:

I do think that if the majority of people who are making the decisions are men, they feel more comfortable with their own, and that's come out a lot. The peer on peer thing, and the stories that they relate to.

Conversely, one of our female interviewees (working in film accounting) in 2011 reported that she had worked almost consistently, except for four months enforced unemployment in early 2010 when many of her contemporaries were in the same situation, irrespective of their backgrounds. Networking has been crucial in her career:

The same people employ me as did before, so although my network of peers has expanded, I tend to be working for the same employers. For my part any decisions around work have been about my personal preferences: Do I like the people I am working with?

Many interviewees observe that the differences in behaviour between men and women have also contributed to the gender imbalance. A female assistant producer expressed the view that men are more confident in selling themselves, while fear of failure hinders the career progression of many women. Some female interviewees suggested that they might not have come across as confidently as the men they were competing against in job interviews. This could have a detrimental effect on their careers as in the freelance world one has to constantly 
attend job interviews and prove oneself. Yet this self-promotion might be felt to conflict with notions of appropriate feminine behaviour (see also Scharff in this volume). As one female assistant producer told us:

The nature of freelancing is that: [...] this is because of the way the interview works, you have to always prove yourself on your jobs. You always have to prove to your next employer [...] to give you a chance, and that can be difficult and I think it's especially difficult for women.

Taken together, these features of the network culture and reputation economies of film and television often serve to disadvantage women. There are strong parallels here with Thanki and Jeffreys' discussion of challenges affecting working class and BAME individuals in the media:

The particularly strong dependence upon informal networking and freelancing still present a number of specific obstacles and barriers to working class people and particularly those from minority ethnic backgrounds. Together these create a web of indirect racism that is dense enough to "push" many of these professionals to quit as the audio-visual industries are predominantly middle-class and their senior posts are still largely run by a largely white "old boy” Oxbridge network (2007: 114).

This is echoed by Randle, Forson and Calveley (forthcoming) who refer to a 'web of reciprocity' in film and television employment, leading to a 'resilient, self-perpetuating habitus' which excludes those without certain cultural and social capital and results in the continual replication of a white, male and middle class industry. Legislation designed to promote and protect gender (and race) equality has a long history in Britain. Equal Opportunity and Equal Pay legislation was passed in the 1970s and, as in many European countries, is backed up by various statutory instruments and bodies at the national as well as European level - most recently the establishment of the Equalities and Human Rights Commission. Yet this raft of legal measures fails to make much impact upon employment in the media and other creative fields. It does not touch or engage with informal practices relating to recruitment and pay, or other enduring inequalities, particularly those reflected in the growing number of small and medium sized companies in production and postproduction. It is often difficult to trace evidence of discrimination in informal recruitment 
practices and even when such evidence can be found, individuals seeking work in 'reputation economies’ may be reluctant to file formal legal challenges.

Major broadcasters, as large corporations, seem more successful in addressing gender and work-life balance. ITV, for instance, reported in 2011 that 48\% of its employees were women, higher than the UK national average of $46 \%$ overall and $38 \%$ for the broadcasting industry, the figures taken from the 2006 Skillset Employment Census. The broadcaster aims to accommodate flexible working requests beyond what is required by law. Any employee who has been employed by ITV for six months or more can apply for a flexible working option. During 2009, 60 applications were approved for flexible working, including nine from men. The company also provides childcare vouchers for qualifying employees.

Despite these initiatives, one entrenched problem then is that they apply predominantly to the very largest organisations, while increasingly the media world is dominated by small production companies or temporary project-based enterprises in which management is enacted informally - with little or no regard for the relevant equal opportunities legislation, let alone dedicated schemes to support underrepresented groups. Eikhof and Warhurst (2013) go so far as to put the project based model of production at the heart of what they see as systemic inequalities in the creative industries. Even when equality and diversity policies are in place, they rarely translate into practice. Reviewing this in the audio-visual industries Holgate and McKay (2009) note that even statements of 'good intentions' such as 'working towards equality' or 'this organisation welcomes applications from all sections of the community' have all but disappeared. In film, television and most other cultural and creative industries people gain and lose jobs in a way that is largely outside the formal apparatuses put in place to protect equality of opportunity. What we see in these fields are what Jones and Pringle (this volume) call ‘unmanageable inequalities' - unmanageable because they exist outwith all the measures designed to deal with them. Our research supports a growing appreciation that informal hiring practices and lack of transparency in appointing and promoting staff is the enemy of equality and diversity.

\section{Parenting and gender inequalities within film and television}

Wreyford (2013: 1) argues: 'It is difficult to talk about women and work without talking about childcare. The same is not true of men and work and this is still one of the most obvious 
difficulties to be managed by working women, even those who choose not to have children'. This brings to the fore one of the dilemmas for feminist analysts in addressing the role that parenting plays in perpetuating gender inequalities: on the one hand, one needs to recognise the continued reality that caring for children is largely undertaken by women, yet on the other, by doing so, one risks re-cementing the relationship between women and children and perpetuating the very gender inequality one wants to critique. This section considers what interviewees had to say about how family responsibilities impacted on their careers, but considers these to be social conventions and thus not essential but open to transformation. We need to remain attentive to the question of why parenting does not negatively impact on men's careers in film and television in the way it does on women's - and guard against this becoming an unquestioned assumption, because it is precisely in the realm of taken-forgrantedness that sexism becomes invisible and naturalised. We seek to draw distinctions between two analytically distinct sets of issues - first the difficulties of balancing creative work and childcare, and secondly the discrimination faced by women because of assumptions about their parental status - or potential to become mothers.

Many of our research participants - both men and women - assumed an automatic connection between gender and childcare, taking for granted the idea that parenting is primarily women's responsibility. This male interviewee is typically 'sympathetic' in highlighting this as 'difficult' for women:

I think women have a lot of difficulty with working freelance because of childcare issues, family care issues [...] it’s not helpful to their careers.

Respondents mentioned a number of different issues - some common across all fields of work, others particular to film and television - such as long hours, very short notice of jobs, and bulimic (Pratt, 2000) patterns of work with intense periods of working around the clock, followed by weeks or months with very little work at all. These interviewees explain:

I think [...] there's a presentee-ism, there's the hours that you work and [...] being available 24/7, which when you have a family, inevitably many women just find it's too much. 
I still think it's an issue, the unfriendly hours, especially if you've got kids around, because we'll routinely have to get up at 4 o'clock in the morning, go out and work a 12 hour day and then get back at 10 o'clock at night.

Some women with children explained the impossibility of finding appropriate childcare for these kinds of hours or working patterns, for example the lack of nurseries for night shift workers or the difficulty of hiring a nanny because of the unpredictability of the flow of work. In this sense findings here echo those of Skillset, which asserts 'it has been impossible to avoid the hypothesis that women have been leaving the industry because of difficulty reconciling a career in the creative industries with raising a family' (2010a: 2). Several female interviewees anticipated dropping out of the industry or trying to take up more permanent roles when they start a family. This young female TV researcher, for instance, discusses how she anticipates her own career path in television:

Television's great while you're young and it's exciting and all the rest of it, but I'm also very family orientated [...] and I do want to eventually get married and have my 2.4 children [...] it's not a career for women with children, I don't think.

Even the most successful, high profile, female filmmakers in the UK, such as Antonia Bird and Gurinder Chadha, comment on children as a barrier for women in the film industry (quoted in Kellaway, 2007):

Chadha: I don't think I would be where I am today if I had had children earlier or had a mortgage. I was living in a rent-controlled apartment until three years ago. If I'd had a huge mortgage and I'd had to service the needs of a family, I wouldn't be where I am.

Bird: I definitely wouldn't be where I am today if I'd had children.

One consequence of this is that the industry still lacks female role models in the upper echelons who have successfully balanced career and family life. One of our interviewees observes:

It's noticeable that women [at the top of in the industry] are not married or have not had children, a lot of them. And does that say, in order to get on, you can’t have children? 
Distinct from the actual practical challenges of maintaining a career in film or television alongside parenting were the difficulties that women faced in overcoming sexist attitudes about the possibility that they might have children. These could take many forms and clearly affect all women, including those who do not become mothers. Common was the assumption that the possibility of young women having children could make it more 'rational' in any given situation to hire a man, because he would be less likely to leave or to take time off. Relatedly, women attempting to find work later on in their careers after taking time off to have a child or children could also be subject to this disadvantage, which would again almost always be glossed as 'reasonable' or 'understandable' - in the manner of 'benevolent' sexism (Glick and Fiske, 1996) or 'new sexism' (Gill, 1993, 2013). As one of our interviewees, in a key hiring position, put it

You put two CVs blind together, one of them will understandably have years more experience than the other because the woman has lost five, six years.

A different kind of sexism can be seen in the assumption that having children in some way 'taints' or absorbs a woman's creative energy or will to succeed. One of our interviewees reports a conversation she had with a commissioning editor in which he said,

I just think [...] a woman of a certain age who's got kids [...] the hunger isn't there anymore, so they'll do you a good enough job but they won't die and fight for the programme.

This sudden diminution of professional hunger or fight is not attributed to men when they become parents, highlighting its one-sidedness and the way it works selectively to justify the exclusion of women. Many interviewees suggest that successful female professionals put their personal life on hold to pursue their careers as gaps in the career affects the freelancers' portfolio. 'Knowing when requires understanding the timing of career choices, to stay or leave, to push forward or pull back' (Jones and DeFillippi, 1996: 99, italic original), but this also means prioritising work over any family considerations. For these reasons, those who have children often do not talk about them for fear of it affecting their careers. In this sense having or wanting children could become unspeakable, prompting situations in which pregnancies were hidden and references to one's children avoided, or in which female workers went back to work soon after giving birth, in order not to have any interruption in 
their career biographies. The costs of this are borne heavily - and often without support - by women, who often feel that they must not talk about these issues. As one interviewee commented, the issues of lack of childcare or proper leave are rarely raised as women do not want to draw attention to these for fear of being labelled a problem, or someone who whinges. The more subtle forms of sexism need to be understood alongside the rightful focus on the characteristics of being labelled a problem. In this way, maternity and caring responsibilities become individualised and privatised 'problems' for women to deal with on their own. This is paralleled more broadly by the ethic of 'getting on with it', not 'moaning' or 'whinging' - in case this made one seem difficult (see also Jones and Pringle this volume). In these ways, women in the industry were silenced and had to become 'responsibilised' entrepreneurial subjects who took on and carried all the costs, risks and challenges of being working parents alone.

\section{Discussion}

In this paper we have examined the lives of freelancers working in the film and television industries, as these industries become increasingly fragmented and casualised. Our interviews demonstrated that freelancing can be challenging for many people, with struggles about endemic job insecurity, anxiety about the flow of work, one's ability to meet financial obligations and stay afloat in a desired career. Here, though, we have sought in particular to understand the role that freelancing may play in exacerbating persistent gender inequalities in film and television. Our analysis is focused upon two broad themes - the informality that characterises the hiring for and securing of jobs in creative media, and the distinct challenges of parenting while working in these fields. Our interviewees highlighted particular challenges that women face in relation to the normalised practices of finding work - challenges that relate to breaking into male dominated fields, to promoting oneself, and to joining or building the networks that are crucial to securing work. Other aspects of the work, including long hours, unpredictable and bulimic working patterns, and a culture of presentee-ism could also pose particular challenges for women with caring responsibilities.

Jones and DeFillippi argue that in the USA, 'the boundaryless career system challenges its participants to improvise their home and hearth around the unpredictable vicissitudes of frenetic project activity and involuntary unemployment' and for many film professionals 'family life had been deferred, denied, or at least compromised during their careers' (1996: 93, 94). The informality of film and television employment has a major impact on 
practitioners, especially women who are often adversely affected by the precarious nature of freelance employment and a male- and network-dominated work place. Work patterns, childcare, money and freelance culture affect women practitioners' decisions to have children or not and whether they are able to sustain a film or media career as parents. While parenting and childcare do not need to be the exclusive responsibility of women, it is striking in our research that few, if any, interviewees discussed this in relation to men, reinforcing assumptions about the gendering of responsibility for childcare. In the UK context, our findings lend support to research from Skillset that highlights motherhood - but not fatherhood - as a key factor in understanding the persistence of gender inequalities in film and television.

However alongside the practical difficulties associated with being a mother in tandem with working in film or television, we have also highlighted the sexism that women face in relation to potential parenthood. This could affect all women regardless of whether they were - or wished to become - mothers, and found no parallel among men. This widespread sexism is based around the assumption that, given male and female candidates with equal CVs, it would be 'rational' or 'understandable' to hire the man. This form of apparently 'reasonable' sexism is difficult for women to address or challenge, both because of its deep roots and the lack of any apparatus to manage it within the informal casualised world of film and television project networks (see Jones and Pringle, this volume). It is further underscored by a culture of silence which makes it very difficult for women to speak out about such issues, since to talk about children or childcare in these environments is potentially to call into question one's commitment to work, or even to be labelled 'difficult'. This highlights the ways in which new, subtle forms of sexism interact with a neoliberal work culture that calls on individuals to be autonomous, entrepreneurial subjects who prioritise work above all else and have an unwritten contract to be mobile, to be flexible, and to take private responsibility for anything that might impede their availability to be on the job $24 / 7$.

Gender is clearly not the only factor influencing media careers. Class, race, age, disability and even geography have profound impacts, sometimes in surprising ways. For example, one disabled female film researcher discussed how it was the fact that she could not (for financial and childcare reasons) live in London that had the biggest impact on her chances within the industry, and not her gender or disability:

Because I have a young family and I live in [a regional city], and there weren't the opportunities to get enough work basically $[. .$.$] as a freelancer, you've got to be in the$ 
nub, you've always got to be networking and keep yourself known to get those offers of work, and I just couldn’t be in the nub because I didn’t live in London.

This paper has focussed on gender while being attentive to the ways in which other intersecting identities are key. It has highlighted in particular the ways in which gender inequality is mediated by age and parental status, while also paying attention to the importance of place and class in the ability to sustain a career in film and television.

Women do 'get in' to film and television, but they still rarely 'get on' as well as their male peers, despite superior qualifications and considerable talent. Women are career 'scramblers' in these fields but set against the more positive associations Jones and DeFillippi (1996) attribute to the 'opportunities' available to the free agent, the term seems more appropriate here to indicate 'without a secure hold'. This is demonstrated by their disproportionate exodus during the recent recession, when women were forced to 'get out' at six times the rate of men (O’Connor, 2010). We hope to have shown some of the factors that contribute to this, and that also - paradoxically - make this very inequality both unmanageable and unspeakable for many women working within these fields.

\section{References}

Beck, U., (2000), The Brave New World of Work, Cambridge: Polity.

Brah, A. and Phoenix, A., (2004), ‘Ain’t I A Woman? Revisiting Intersectionality', Journal of International Women's Studies 5 (3): 75-86.

Blair, H., (2000), 'Working in Film: Employment in a Project-based Sector', Personnel Review 30 (2): 170-185.

British Film Institute, (2013), BFI Statistics Yearbook 2013, London.

CIRCU, (2008), Report on the Training Needs of Freelancers, for Broadcast Training \& Skills Regulator.

Creative Skillset, (2012), Employment Census of the Creative Media Industries, London.

Crenshaw, K., (1991), 'Mapping the Margins: Intersectionality, Identity Politics, and Violence against Women of Color', Stanford Law Review 43 (6): 1241-1299.

Eikhof, D. and Warhurst, C., (2013), 'The Promised Land? Why Social Inequalities are Systemic in the Creative Industries’ Employee Relations, 35 (5): 495-508.

Equality and Human Rights Commission, (2011), Sex and Power 2011: Who Runs Britain? Leeds: Centre for Women and Democracy. 
Gill, R., (1993), 'Justifying Injustice: Broadcasters‘ Accounts of Inequality in Radio', in Burman, E. and Parker, I. (eds), Discourse Analytic Research: Readings and Repertoires of Texts in Action, London: Routledge: 75-93.

Gill, R., (2002), 'Cool, Creative and Egalitarian? Exploring Gender in Project-Based New Media Work in Europe’, Information, Communication \& Society, 5(1): 70-89.

Gill, R., (2014), 'An Ideological Dilemma: The Resurgence of Sexism and the Disappearance of 'Sexism'” in Antaki, C. and Condor, S. (eds), Rhetoric, Ideology and Social Psychology: Essays in Honour of Michael Billig. London: Routledge: 109-121.

Gill, R., (2015), 'Unspeakable Inequalities: Postfeminism, Entrepreneurial Subjectivity and the Repudiation of Sexism among Cultural Workers', Social Politics.

Glick, P. and Fiske, S., (1996), 'The Ambivalent Sexism Inventory: Differentiating Hostile and Benevolent Sexism', Journal of Personality and Social Psychology, 70 (3): 491-512.

Gregg, M., (2006), 'On Friday Night Drinks: Neoliberalism's Compulsory Friends’, Paper presented at the UnAustralia Conference of the Cultural Studies Association of Australasia.

Grugulis, I. and Stoyanova, D., (2010), ‘ “I Don’t Know Where You Learn Them”: Skills in Film and TV', in McKinlay, A. and Smith, C. (eds), Creative Labour, Basingstoke, Hampshire: Palgrave MacMillan: 135-155

Holgate, J. and McKay, S., (2009), 'Equal Opportunities Policies: How Effective are They in Increasing Diversity in the Audio-visual Industries' Freelance Labour Market', Media, Culture and Society, 31 (1): 151-163.

House of Lords Select Committee on Communications, (2010), The British Film and Television Industries - Decline or Opportunity? Volume II: Evidence, London: House of Lords.

Jones, C. and DeFillippi, R.J., (1996), 'Back to the Future in Film: Combining Industry and Self-Knowledge to Meet the Career Challenges of the $21^{\text {st }}$ Century', Academy of Management Executive, 10 (4): 89-103.

Kellaway, K., (2007), 'Celluloid Ceiling? Ask the Experts’, The Observer, March 4.

Lauzen, M., (2012), The Celluloid Ceiling: Behind-the-Scenes Employment of Women on the Top 250 Films of 2012, San Diego: Center for the Study of Women in Television \& Film.

Neff, G., (2012), Venture Labor: Work and the Burden of Risk in Innovative Industries, Boston: MIT.

Oakley, K., (2013), 'Absentee Workers: Representation and Participation in the Cultural Industries', in Banks, M., Gill, R. and Taylor, S. (eds), Theorizing Cultural Work. Labour, Continuity and Change in the Cultural Industries, London: Routledge: 56-67.

O’Connor,K. (2010) Speech to Women in TV Debate, BAFTA, London, March 17, available at: $\quad$ http://www.bafta.org/access-all-areas/women-working-in-tv-is-it-a-young-girlsgame,1048,BA.html 
Ofcom, (2006), Review of Television Production Sector Consultation Document, London: Ofcom.

Ofcom, (2010), The Communications Market 2010. 2. TV and Audio-Visual. London: Ofcom.

Pratt, A., (2000), 'New Media the New Economy and New Spaces', Geoforum, 31 (4): 425436.

Randle, K. (2011) 'The Organisation of Film and Television Production' in Deuze, M. (ed) Managing Media Work, Los Angeles:Sage

Randle, K. and Culkin, N., (2009), 'Getting In and Getting On in Hollywood: Freelance Careers in an Uncertain Industry', in McKinlay, A. and Smith, C. (eds), Creative Labour, London: Palgrave Macmillan: 93-115.

Randle, K., Forson, C. and Calveley, M., (forthcoming). 'Towards a Bourdieusian Analysis of the Social Composition of the UK Film and Television Workforce', Work, Employment and Society.

Randle, K., Leung, W., and Kurian, J., (2007), Creating Difference: Overcoming Barriers to Diversity in UK Film \& Television Employment, Report to European Social Fund.

Ross, A., (2009), Nice Work if You Can Get It: Life and Labor in Precarious Times, New York: New York University Press.

Sargent-Disc, (2011), Age and Gender in UK Film Industry, available at: http://www.sargentdisc.com/sargent-disc-uk/news-insights/insights/uk-film-industry-age-and-gender.aspx

Skillset, (2010a), Women in the Creative Media Industries. London: Skillset.

Skillset, (2010b), Women Working in Television. London: Skillset, available at: http://guru.bafta.org/women-working-television-debate

Skillset, (2010c), Film Sector - Labour Market Intelligence Digest, Skillset: London.

Skillset, (2011), Television Sector - Labour Market Intelligence Profile, Skillset: London.

Skillset/UKFC, (2008), Feature Film Production Workforce Survey Report 2008, London: Skillset/UKFC.

Thanki, A. and Jeffreys, S., (2007), 'Who are the Fairest? Ethnic Segmentation in London's Media Production’, Work Organisation, Labour and Globalisation, 1 (1): 108-118.

Wittel, A., (2001), ‘Towards a Network Sociality’, Theory Culture \& Society, 18 (6): 51-76.

Wreyford, N., (2013), 'The Real Cost of Childcare: Motherhood and Project-based Creative Labour in the UK Film Industry', Studies in the Maternal, 5 (2), available at: http://www.mamsie.bbk.ac.uk/documents/Wreyford_SiM_5(2)2013.pdf 